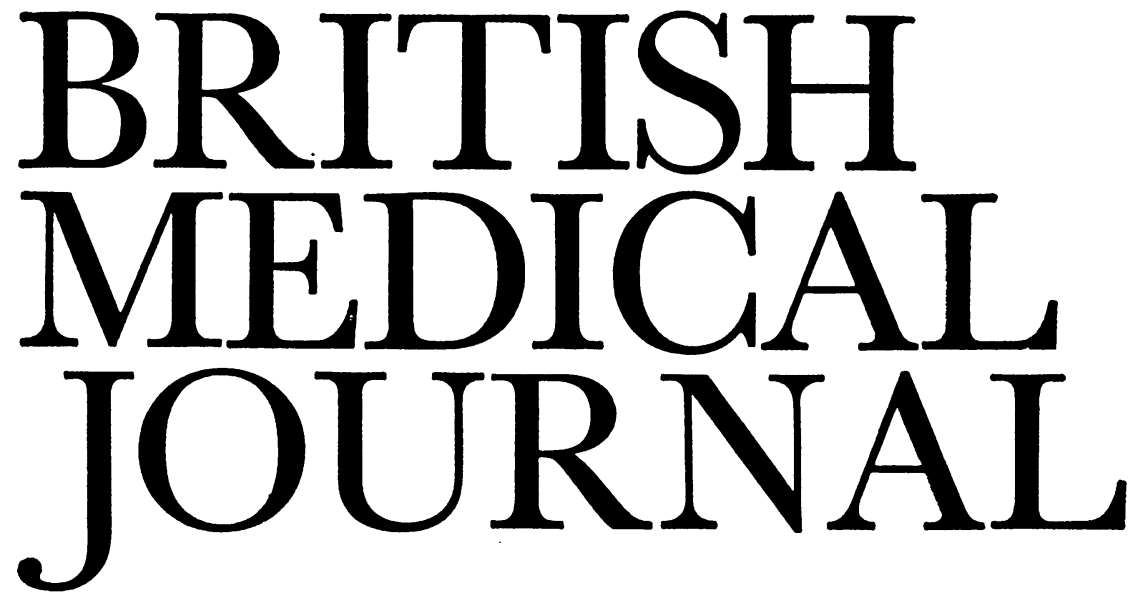

LONDON SATURDAY 31 JULY 1971

\title{
Abortion or Contraception?
}

Abortion is a growth industry in Britain. There were 25,000 legal terminations of pregnancy in the first eight months after the Act came into operation; 58,000 in $1969 ; 92,000$ in 1970; and there is no sign that the rate of growth is slackening. ${ }^{1}$ Evidence from other countries which have made abortion freely available suggests that a level of between $20 \%$ and $60 \%$ of the birth rate may be maintained year after year. ${ }^{2}$ Current estimates ${ }^{3}$ of the number of unwanted pregnancies in Britain are between 200,000 and 300,000, and if abortion on demand became a reality the number of terminations each year could easily approach the quarter million mark.

The fastest rise in the incidence of abortion is among teenage girls, ${ }^{4}$ and in the under-sixteens there has also been a recent rise in the number of illegitimate births. Those who favour freer abortion argue that cutting red tape would speed the process of referral, so allowing abortion to be done earlier in pregnancy, when techniques such as vacuum aspiration can be used, possibly on an outpatient basis. This view glosses over the sequelae of abortion. In his presidential address, printed at p. 267, Sir John Peel points out that complications such as haemorrhage, trauma, and infection are greater risks when first pregnancies are terminated in the young, and that the long-term hazardsinfertility, spontaneous abortion, and premature deliveryare of greater consequence to young girls than to older women who have already had a family. The long-term psychological consequences of unintended pregnancies in the young-whether terminated or not-are unknown, and Sir John urges that these problems, too, should be studied.

The practical effects of the boom in abortions are not disputed. A few doctors in private practice are making a lot of money, but the five to six hundred N.H.S. gynaecologists are not so happy. ${ }^{5}$ They were scarcely underworked before the Abortion Act; nor were their waiting lists unusually short. Yet with the same number of outpatient and operating sessions time has to be found for women seeking abortions. Gynaecologists who believe that each case should be treated on its merits find that it may take 30-45 minutes of history-taking and examination to reach a decision, and in those for which abortion seems right there has to be referral for a second opinion, generally from a psychiatrist, and the surgeon must find operating time and a bed. This time can be found only at the expense of other patients with "less urgent" conditions-prolapse, incontinence of urine, fibroids -all of which cause distress and for which waiting lists are long enough anyway.

Any further substantial rise in the numbers of abortions in Britain would impose an impossible load on the present system. In British Columbia last year a hospital operating a liberal abortion policy found that one-quarter of the operations in its gynaecological lists were abortions or sterilizations. ${ }^{6}$ Not all gynaecologists find abortion ethically acceptable; and a further minority will terminate pregnancy only in the presence of a clear-cut threat to the life of the mother. ${ }^{5}$ In Britain at present this leaves the remainder with an average of 150 or more abortions each yearand further consultations where an abortion is refused. Any gynaecologist must be free to assess the relative claims of his patients with chronic disease and of women who have unintentionally become pregnant. Criticisms in the press of doctors who "refuse" abortion too often ignore this fundamental right to exercise professional judgement.

Widespread adoption of a policy of abortion on demand would, then, stress gynaecologists, who are already overworked, and carry appreciable hazards for the health of the women concerned, particularly if young. What is the solution?

It is no answer to say that women must pay for their mistakes and have the babies. Yet gynaecologists may be forgiven for thinking that when they are pressed for operating time they should give low priority to women who have become pregnant because they could not be bothered to use effective contraceptives-and in some series ${ }^{7}$ as many as three-quarters of women having abortions used no form of contraception. But the 200,000 unwanted pregnancies a year in Britain is a disturbingly high figure: and some at least will become unwanted children at special risk of becoming delinquent, antisocial adults. ${ }^{8}$ A two-fold campaign is called for. Firstly-and perhaps this may not be ponular in a society which too rarely acknowledges fault or personal responsibility-doctors should encourage the attitude that unless a child is really wanted sexual intercourse without contraception is an act of selfish irresponsibility by both parties. Slowly society is accepting that a drunken driver has no excuse. A drunken or couldn't-care-less parent is just as culpable. Effective contraception is available, and there should be no excuse for unintentional pregnancies.

At present, however, there is an excuse, and that is that contraceptive advice and apparatus are not readily available to all, particularly the very young. Pioneering work by the 
Family Planning Association and the Brook Centres has largely failed to contact social classes 4 and 5-who make up the greater part of the population. Local authorities were given power under the Family Planning Act of 1968 to set up birth control clinics, but few seem to have done so. Sir John Peel comments that "gynaecologists as well as general practitioners are getting more and more incensed by the increasing demand that they should recommend and carry out abortions within the Health Service for purely social convenience and yet are prevented from prescribing the drugs and issuing the appliances necessary for effective contraceptive practice as freely within the Health Service as any other drugs and appliances, unless there exists what is called a medical indication." Is this the answer? Is there a good case for including contraceptives in the N.H.S. whatever the indication?

If it became accepted that "you get your contraceptives from your G.P." there might be less embarrassment about asking for them. Family doctors know how often mothers of problem families are advised to use contraceptives but do not: the logical solution is for the doctor himself to do something about it. He can recognize many patients at risk as they come into his surgery for routine consultations: he should be able to offer them a prescription or fit an appliance on the spot. Just as important is contraceptive advice for women in hospital for abortions or delivery of babies. Referring the patient to a clinic or another doctor too often means that nothing is done.

A major objection to free contraception is the costperhaps $£ 20$ million a year-described by the Secretary of State as a gratuitous waste of taxpayer's money. Some doctors may argue that people should be encouraged to take more and not less personal responsibility, and that free contraceptives would be yet another example of the mollycoddling of the Welfare State. But how many abortions and illegitimate births would need to be prevented to balance the account? The effects of such a change can only be guessed at, yet no other alternative has been put forward which seems likely to have any significant effect on the current rising trends in unwanted pregnancies. A second objection is that family doctors, already overworked, would be asked to take on yet another item of service. Again the effects can only be estimated, but there should be some reduction in the number of consultations for abortion. It would certainly help if the Review Body could be persuaded to price this service.

So this would be the bargain. On the one hand doctors should refuse to compromise their principles and should not accede to popular pressure for abortion on demand. This attitude can be supported only by an unambiguous commitment by Government, family doctors, and gynaecologists to offer contraceptive advice and appliances within the N.H.S. to all comers (with the proviso that in this field as in any other, sincerely hold religious convictions must be respected, and that most doctors will do their best to dissuade teenagers from sexual experience at too early an age). Once such a service is available, unprotected sexual intercourse resulting in unplanned pregnancy can be seen for what it is in an age of effective contraception-an example of thoughtless self-indulgence.

1 British Medical fournal, 1971, 2, 478.

- Borrie, W. D., The Growth and Control of World Population. London, Weidenfeld and Nicolson, 1970.

s Select Committee on Science and Technology, First Report: Population of the United Kingdom. London, H.M.S.O., 1971.

- Registrar General's Statistical Review of England and Wales for the year 1969: Supplement on Abortion. London, H.M.S.O., 1971.
- Findings of an Inquiry into the First Year's Working of the Act conducted by the Royal College of Obstetricians and Gynaecologists. British Medical fournal, 1970, 2, 529 .

- Claman, A. D., Wakeford, J. R., Turner, J. M. M., and Hayden, B., Canadian Medical Association fournal, 1971, 105, 35.

7 Diggory, P. L. C., Lancet, 1969, 1, 873.

British Medical fournal, 1971, 2, 484.

\section{The Masai's Cholesterol}

The Masai of East Africa have long held a particular fascination for the visitor as well as the scientist because of their physical and cultural characteristics and their adherence to a traditional nomadic way of life. Over the past decade there has been considerable interest in the dietary habits and physical activity patterns of the nomadic peoples of East Africa (of which the Masai are one) in relation to hypotheses about atherosclerosis and coronary heart disease. Their nomadic pastoralism entails a fair amount of physical activity, and their diet consists of meat, milk, and blood. This clearly is a natural setting for the investigation of diet, blood cholesterol levels, and atherosclerosis. The most recent report on the Masai, ${ }^{1}$ summarizing studies which will appear in greater detail elsewhere, ${ }^{2}$ has a bearing on the general problem of atherosclerosis in man.

The story as presented is as follows. The Masai have a staple diet of milk, meat, and blood. The milk contains a fairly high proportion of total lipid, phospholipids, and cholesterol. The average daily calorie intake is about 3,000, with $66 \%$ of calories derived from fat. The average daily cholesterol intake is 500 to $2,000 \mathrm{mg}$, which is comparable to the average in the U.S.A. Despite their customary highfat diet the aortas and coronary arteries of the Masai show little atherosclerosis. Serum cholesterol levels are low, with no increase in level with increasing age. The serum levels of beta-lipoprotein are low and of pre-beta-lipoprotein low or absent. Pregnant Masai women show no increase in serum cholesterol level in the first and second trimesters of gestation, but in the third trimester there is a $50 \%$ increase over the non-pregnant level.

An experiment was designed to investigate "the basic mechanisms that protect the Masai from hypercholesterolaemia on a diet rich in cholesterol and animal fat during their entire lifetime". Masai students, aged 18 to 24, at an agricultural school were divided into two groups and given a basic diet low in saturated fats and free of cholesterol. One group received $2 \mathrm{~g}$ crystalline cholesterol daily with a trace dose of cholesterol-4-14 $\mathrm{C}$ mixed in the basic diet, and the other group received only the trace dose of cholesterol-4-14 C in the diet. The trace dose was discontinued after eight weeks, and the decreasing curve of tracer activity was followed for another six months. The amounts of cholesterol absorbed, synthesized, and excreted per day were calculated from weekly blood and stool samples, and turnover times and pool sizes of the total body exchangeable cholesterol were determined.

Despite the daily dose of $2 \mathrm{~g}$ cholesterol to the experimental group the results showed no significant difference between the two groups in serum cholesterol, phospholipid, triglyceride levels, and lipoprotein patterns. The size of the exchangeable body cholesterol pools of the two groups remained constant, and the turnover times and turnover rates of body cholesterol were the same. But endogenous synthesis of cholesterol in the experimental group was about half that in the control subjects. The investigators concluded that this suppression of synthesis of cholesterol by 